\title{
A closer look at the relationship of entry-level bank employees' leadership attributes and customer satisfaction
}

\author{
Majda I. Ayoub Al-Salim ${ }^{1}$
}

Revised: 3 June 2018/Published online: 3 July 2018

(C) The Author(s) 2018

\begin{abstract}
The purpose of this quantitative research was to measure customer satisfaction with bank tellers and bank teller leadership attributes and to determine the relationships between the two and the effect of gender on the ratings. Data were collected at three bank branches in West Amman-Jordan with 126 bank customers. The results revealed statistically significant differences in the ratings of the leadership attributes: Ethics had highest ratings while innovation had the lowest ratings. There were significantly different gender ratings in two leadership attributes such that women's ratings were higher than the men's in bank knowledge and communication leadership attributes. Also, men and women differed significantly on satisfaction; women were more satisfied than men. Moreover, results revealed that satisfaction correlated directly, strongly, and significantly with all five leadership attributes. Additionally, results showed that bank knowledge, innovation, and gender all made unique and statistically significant contributions to predicting satisfaction with bank tellers.
\end{abstract}

Keywords Entry Level employees · Leadership Attributes · Customer Satisfaction

\section{Introduction}

Research indicates that corporations' success is critically linked to leadership attributes. Georgescu and Dorsey (2005) argued that leadership attributes such as open-

Majda I. Ayoub Al-Salim

m.ayoub@aum.edu.jo

1 American University of Madaba, P.O. Box 2882, Amman 11821, Jordan mindedness, trust, creativity, and ethics, among other qualities, may be an influence to transform the way organizations do business. Employees with favorable leadership qualities may encourage breakthroughs needed to grow profits above the surplus mark (Georgescu and Dorsey 2005). Followers are drawn to employees, according to Banther (2014), with leadership qualities such as openness and willingness to spend time as well as those who are listeners and always inspire others. Employees who demonstrate the latter leadership attributes bring financial gain to the company (Banther 2014).

Customer service is imperative to all organizations as it is thought to be associated with customer satisfaction. The dominant view of scholars in the consumer behavior research proposes that satisfaction and quality of service are indeed related (Graefe and Burns 2013). Higher quality of service is needed for today's business environment. Okoe et al. (2013) argued that offering quality service is an essential part of continuing strategy of the majority of corporations and is a vital element for survival as well as success in today's competitive environment. When the product attributes are boosted through other customer service qualities, it increases customer satisfaction which leads to customer retention and loyalty (Liang and WenHung 2004). O'Sullivan and McCallig (2012) concluded that a company's value is influenced by the company earnings, customer satisfaction, and the collaboration between the two. Additionally, employees who are in contact with customers or facing them are at the forefront as they present the face of the company they work for and serve as main connectors between the customer and the leadership in any organization. Some studies indicate a significant relationship between the employee involvement, commitment, and vision-guiding and customer and employee satisfaction (Cheema et al. 2015). Medina (2010) 
concluded that both leadership attributes and customer satisfaction have a significant relationship. When a customer is highly satisfied with a product or service, there is a possibility that he or she may carry out brand evangelism. Brand evangelism, according to Doss (2014) is a strong, positive word-of-mouth message communicated to prospective customers.

The purpose of this research was to explore, through the use of statistical analysis, if there was any significant relationship or correlation between bank tellers' leadership attributes and customer satisfaction levels. This was a quantitative descriptive correlational research with a nonrandom sample of 126 participants who were surveyed at three different bank branches. The participants were bank customers in a local bank in Amman, Jordan.

\section{Literature review}

Corporations that continue to develop leaders are among the most profitable companies in their fields (Woolfe 2002). A character of a true leader, according to Baldoni (2008), forms the foundation for leadership: without it, leadership is dreadful; with it, leadership may prosper (Baldoni 2008). Covey (1989), the author of The Seven Habits of Highly Effective People argued that soft skills and hard skills are equally needed for employees handling projects; leadership is among the key attributes of soft skills along with good communication, innovation, and teamwork. Good leadership necessitates presentation skills and assumes sophisticated soft skills to effectively manage resources (Nelson 2013).

Leadership has evolved through history, and in the USA during the 1900s, many studies indicated that leadership is essential in organizations (Landis et al. 2014). Although the term leader was evident as early as the $1300 \mathrm{~s} \mathrm{AD}$ and theorized to have been used even before biblical times, the term leadership did not originate until the late seventeenth century (Badshah 2012). According to Woolfe (2002), during Old Testament times, nations flourished when their leaders were leading ethically according to plan; however, when leaders performed poorly and deviated from their mission, their followers suffered and became oppressed. The leadership both during biblical times and today included the most shrewd business and public leaders and required capable and established leaders with the right qualities and morals following in their footsteps (Woolfe 2002).

Customers' needs are constantly evolving due to the ease of information access, such as the Internet, which created a well-informed customer. One thing remains of great concern to the customer and that is the organizational behavior as it affects customer satisfaction (Ambroz and
Praprotnik 2008). An ethical climate may be an aspect that influences the satisfaction of customers and snowballing monetary performance through encouraging employees' innovative behaviors. Karlsson and Skålén (2015) argued that frontline employees have the ability to create value with their customers. Consequently, some argue that frontline employees are appropriate for a positive contribution to organizations' service innovation. Frontline employees with technical product knowledge may capitalize on the customer and the firms' benefits (Karlsson and Skålén 2015). The frontline employees are the most knowledgeable of customers' concerns and problems and capable of solving such issues in a creative and practical way (IANS 2015). Strategically, according to Leelawong (2011), creativity of employees in a very competitive business world may be the basis of continuous competitive advantage since such creativity assists in product and processes. These strategic attributes of employees with ideas and innovation make them a significant resource in an organization (Leelawong 2011). Customer satisfaction involves having customers who are happy enough to advertise voluntarily in their communities and who persuade others to purchase the product (Jackson 1993). When a customer is satisfied, it is difficult to change his or her opinion otherwise. For example, Festinger's theory of cognitive dissonance covers individuals' motives and the desire for agreement among attitudes, opinions, feelings, and behaviors; once a customer develops particular views, he or she inclines to be steady and resilient to change ( $\mathrm{Li}$ and Murphy 2013). Customer satisfaction occurs when a product or service exceeds the expectations the consumer had prior to purchase (Jackson 1993). Customer satisfaction is viewed as a function of service quality; it is the connection between service quality and post-purchase phenomena which affects the customer attitude toward the product, purchase recurrence, and brand loyalty (Hui et al. 2013). Vroom's expectancy theory emphasizes the significance of motivation (Lee 2007). Expectancy theory has three main components: valence, expectancy, and instrumentality. Valence was explained by Vroom as effective orientation for particular outcomes, and expectancy is clarified as a brief belief followed by a specific outcome (Lee 2007). Instrumentality, however, describes the belief that this performance is required to achieve a particular goal or an outcome (Hsu et al. 2014). Vroom's expectancy model has great value for marketing research since it offers some solutions on how to inspire customers to use a particular product. Customer loyalty is another concern for today' firms. Coelho and Henseler (2012) concluded that service customization is an essential part of customer loyalty. Also, according to the theoretical approach of customization outcomes, the influence of customization on loyalty is partly facilitated by perceived service quality, 
customer satisfaction, and trust. Coelho and Henseler also concluded that customization is a significant predictor of perceived quality, satisfaction, trust, and customer loyalty. It is notable that the total effect of customization on customer loyalty offsets the total effect of quality (Coelho and Henseler 2012).

Many scholars from different fields of study, according to Raab et al. (2012), found remarkable results on customer satisfaction, which include that it is approximately $600 \%$ more costly to attain new customers than to retain the current ones. Satisfied customers have about a 300\% higher chance of remaining customers with the same company than it is with unsatisfied customers because satisfied customers bring in referrals. Similarly, $95 \%$ of irritated customers will remain loyal if their issue is resolved within 5 days and $75 \%$ of customers who shift to the competition do so as a result of low service quality (Raab et al. 2012).

Additionally, many studies have been conducted which indicate that gender plays a significant role in ratings using questionnaires. Such phenomenon may be attributed to the different priorities and needs males and females have. Aljazzazi (2017) assessed differences in quality perceptions of bank services utilizing different Jordanian bank customers. Al-jazzazi used several demographic variables and among them was gender. The findings revealed that bank service quality was significantly different based on the gender variable (Al-jazzazi 2017). Another study was conducted by Mokhlis (2012) on the five service quality dimensions; three of these dimensions were empathy, tangibles, and reliability. Mokhlis concluded that gender differences were significant. Male customers conferred greater importance to the aforementioned dimensions than did female customers (Mokhlis 2012).

\section{Methodology}

The study took place at a local bank at three different branches in West Amman, Jordan, and local bank customers who were 18 years or older were asked to fill out the survey. The first few days were designated for a pilot study. The sample population surveyed was 126 participants in Amman, Jordan, and a 6-point Likert scale survey that consists of 23 6-point Likert scale questions with answers ranging from 1 (strongly disagree), 2 (moderately disagree), 3 (slightly disagree), 4 (slightly agree), 5 (moderately agree), and 6 (strongly agree) was used as a tool for data collection. The questionnaire also included demographic information. A pilot study was completed prior to conducting the actual study in order to obtain feedback on the survey and the procedure. The participants in the pilot study were not counted as part of the sample size, and all the incomplete surveys were disregarded.
Research Questions and Hypotheses There were five research questions used to frame the study. They are presented below with corresponding hypotheses.

Research Question 1 Which bank teller leadership attributes were rated the highest? The lowest?

$\mathrm{H}_{0} \quad$ There is no statistically significant difference in the ratings of the five leadership domains

$\mathrm{H}_{1} \quad$ There is a statistically significant difference in the ratings of the five leadership domains

Research Question 2 Do ratings of teller leadership attributes differ by customer gender?

$\mathrm{H}_{0} \quad$ There is no statistically significant difference in ratings in teller leadership attributes between male and female bank customers

$\mathrm{H}_{1} \quad$ There is a significant difference in teller leadership attributes ratings between male and female bank customers

Research Question 3 Do ratings of customer satisfaction differ by customer gender?

$\mathrm{H}_{0} \quad$ There is no statistically significant difference in customer satisfaction ratings between male and female bank customers

$\mathrm{H}_{1} \quad$ There is a statistically significant difference in customer satisfaction ratings between male and female bank customers

Research Question 4 Is there a relationship between bank teller leadership attributes and customer satisfaction among local bank customers in a bank located in Amman, Jordan?

$\mathrm{H}_{0} \quad$ There is no statistically significant relationship between bank teller leadership attributes and bank customer satisfaction

$\mathrm{H}_{0} \quad$ There is a statistically significant relationship between bank teller leadership attributes and bank customer satisfaction

Research Question 5 Is overall bank customer satisfaction explained by teller leadership behavior?

$\mathrm{H}_{0} \quad$ There is no statistically significant relationship between customer satisfaction in Amman, Jordan, and the leadership attributes of tellers

$\mathrm{H}_{1} \quad$ There is a statistically significant relationship between customer satisfaction of the local bank customers in Amman, Jordan, and the leadership attributes of tellers 
In the present study, this researcher asked multiple, yet similar, questions on each leadership attribute and customer satisfaction on the survey to establish reliability. No measure is $100 \%$ reliable; however, it is important to identify the degree of reliability to allow for the degree of error that exists.

To assess data quality for this research, reliability valuation was an indispensable step in the analysis of the data. The value of alpha $(\alpha)$ at .05 is a widely used indicator of reliability. The Cronbach's alpha reliability statistics ranged from .7 to .88 , which indicated a reliable database.

For this study, statistical significance was set at $\alpha=.05$ and the sample size was 126 . The minimum sample size was established based on the calculations found in SurveyMonkey (2016): Where $n$ denotes sample size, $p$ : proportion of the population $=.5, Z=1.96$ which is the $z$ score for confidence level of $95 \%$ and $E$ denotes the margin of error percentage which is $0.1==>n=$ $p(1-p) \quad(Z / E)^{2}==>0.5 * 0.5^{*}(1.96 / 0.1)^{2}==>96.04$. Therefore, $n=97$ as a minimum sample needed. A nonrandom sample from the population was chosen to fill out the survey.

\section{Limitations}

The scope of the study was limited to the sample participants taken out of the three local bank branches in Amman, Jordan. The answers produced as a result of filling out the survey instruments were limited to the honest replies on the survey. Also, prior experiences of participants might have affected the objectivity of their responses to the survey questions. This study was also limited by the number of customer responses which might have affected the reliability of the data collected. Due to cultural differences, the study results, conclusions, and recommendations might be beneficial mainly to organizations in the Middle East and North Africa (MENA) region.

\section{Results}

The satisfaction with bank tellers survey listed four survey items per leadership attribute, and three items for customer satisfaction. The internal consistency or reliability of conceptually related items for each attribute and for satisfaction was checked with Cronbach's alpha $(\alpha)$. Values for
Table 1 Survey items for creating leadership attribute SSs and reliability statistics

\begin{tabular}{ll}
\hline SS and corresponding survey items & Cronbach's $\alpha$ \\
\hline Bank knowledge SS & .79 \\
Understands my banking needs & \\
Addresses my banking needs efficiently & \\
Addresses my banking needs accurately & .70 \\
Knowledgeable about bank products and services & \\
Communication SS & \\
Communicates clearly and effectively & \\
Listens to my suggestions and ideas & .81 \\
Educates me on bank products and services & \\
Exhibits appropriate professionalism & \\
Respect SS & \\
Appears motivated to help me & \\
Shows appropriate professional responsiveness to me & .83 \\
Treats me with respect & \\
Treats me as a valued customer & \\
Ethics SS & \\
Values ethics & \\
Handles procedures with honesty & \\
Exhibits good leadership attributes & \\
Conducts bank business with integrity & \\
Innovation SS & \\
Hooks for ways to maximize my benefits & \\
Serves my banking needs with innovation & \\
\end{tabular}


Cronbach's alpha range from 0 to 1 . The closer Cronbach's alpha is to 1 , the greater the reliability of the database. Table 1 shows indices of .70 or higher which reflects an adequately reliable database.

\section{Demographic results}

A total of $N=126$ bank customers agreed to complete the survey, with $70 \%(n=88)$ male participants and $30 \%$ $(n=38)$ female participants. Bank customer participants were in their late $30 \mathrm{~s}$ on average, $M=37.27$ years of age, $\mathrm{SD}=10.98, \min =20$ years old, $\max =76$ years old. The survey participants had banked with the branch where they were surveyed less than 4 years on average, $M=3.83$ years, $\mathrm{SD}=3.96, \min =5$ months, $\max =25$ years.

Figure 1 is an illustration of the distribution of bank customers' highest educational level and shows that more than half of the customers held a bachelor's degree $(n=69)$ followed by high school diploma or master's degree, $(n=18)$, respectively. Fewer than one in five had attended community college. Remaining participants held doctorates, were physicians, or had ended their education with middle school.

A repeated measures ANOVA test was used to address Research Question one or RQ1. Repeated measures ANOVA tests serve to compare three or more dependent variables, which are the same variables (e.g., measured at different times) or are conceptually related, to determine if they are significantly different. In this study, the assumption of sphericity was examined by comparisons of two versions of the epsilon index, the Greenhouse-Geisser and Huynh-Feldt epsilon statistics (Fig. 2).

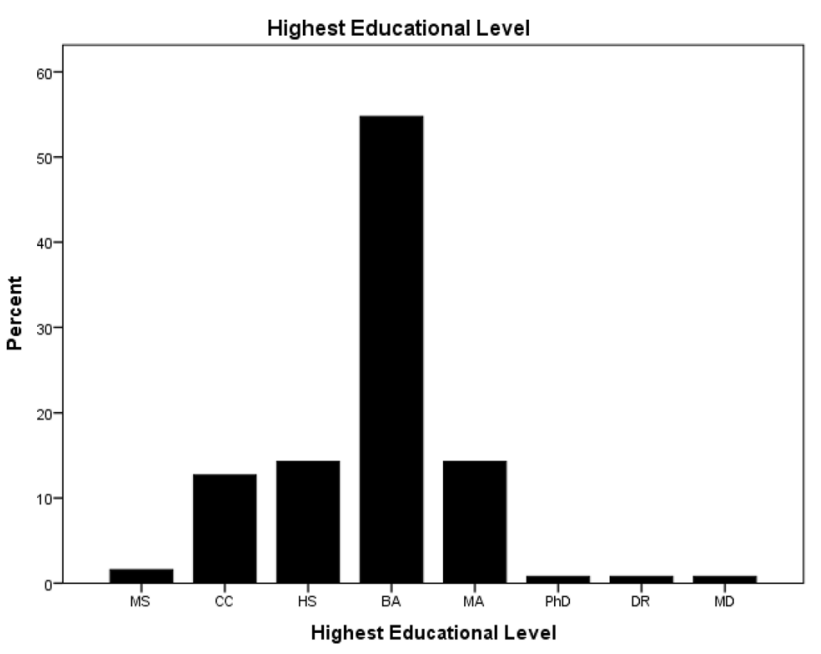

Fig. 1 Distribution of bank customers by highest educational level. $M S$ middle school, $C C$ associate's degree from a 2-year community college, $H S$ high school diploma, $B A$ bachelor's degree, $M A$ master's degree, $P h D$ doctor of philosophy, $M D$ physician, $D R$ doctorate

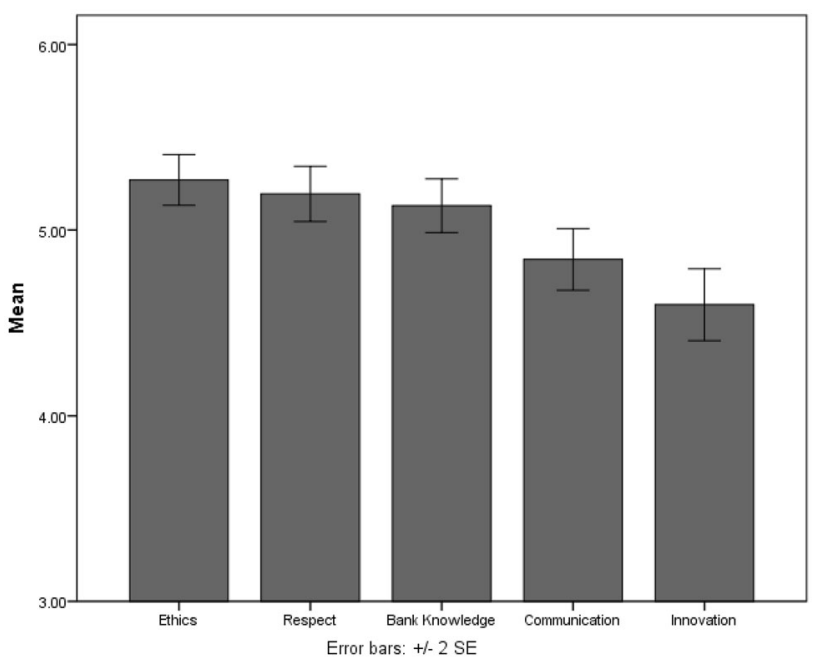

Fig. 2 Mean leadership attribute ratings

Table 2 shows more details with a range of descriptive statistics on the leadership attributes SS, also listed in descending order by the means. The leadership attribute with the highest rating, Ethics, was followed by Respect and Bank Knowledge, respectively, whose means were close in value to each other and to Ethics. Communication and Innovation garnered the two lowest ratings. The maximum statistics in Table 2 show that at least one participant strongly agreed that the tellers he or she interacted with showed the attribute. The minimum statistics in Table 2 show that at least one participant strongly disagreed that tellers were innovative, and at least one participant moderately disagreed that tellers were ethical, respectful, had good working knowledge of banking, or showed reasonable communication.

\section{Inferential comparison of leadership attributes}

A repeated measures ANOVA was run to compare attribute ratings to determine if there was a significant difference among the means.

Results of the repeated measures ANOVA test showed that there were statistically significant differences in the ratings of the five leadership domains, $F(4,500)=39.61$, $p<.001$. Therefore, the null hypothesis was rejected. The impact of the different attributes was very strong, partial $e t a^{2}=.24$.

Planned comparisons were generated with paired sample $t$ tests to identify significantly different pairs of leadership attributes. Table 3 shows that every pair of leadership attribute means was significantly different with only two exceptions. Bank Knowledge and Respect ratings did not differ. Respect and Ethics ratings did not differ. Otherwise, bank customers agreed more strongly that tellers were 
Table 2 Descriptive statistics for ranking leadership attributes and satisfaction
Table 3 Planned comparisons with paired samples $t$ tests and correlations for leadership attributes $(d f=125)$

\begin{tabular}{lrrcccc}
\hline & Ethics & Respect & Bank knowledge & Communication & Innovation & Satisfaction \\
\hline Mean & 5.27 & 5.19 & 5.13 & 4.84 & 4.60 & 5.16 \\
SD & 0.77 & 0.83 & 0.81 & 0.93 & 1.09 & 0.87 \\
Skew & -1.54 & -1.48 & -1.16 & -1.04 & -1.05 & -1.24 \\
Kurtosis & 2.66 & 2.38 & 1.55 & 0.86 & 0.95 & 1.62 \\
Minimum & 2.25 & 2.00 & 2.25 & 2.00 & 1.00 & 1.67 \\
Maximum & 6.00 & 6.00 & 6.00 & 6.00 & 6.00 & 6.00 \\
\hline
\end{tabular}

Descriptive statistics based on SSs. $N=126$ participants

\begin{tabular}{|c|c|c|c|c|c|c|c|c|}
\hline & \multirow[t]{3}{*}{$r$} & \multicolumn{5}{|c|}{ Paired differences } & \multirow[t]{3}{*}{$t$} & \multirow[t]{3}{*}{$p$} \\
\hline & & \multirow[t]{2}{*}{$M$} & \multirow[t]{2}{*}{ SD } & \multirow[t]{2}{*}{ SEM } & \multicolumn{2}{|c|}{$95 \%$ CI diff } & & \\
\hline & & & & & LB & UB & & \\
\hline Bank Knowledge: Communication & $.69 * *$ & .29 & .69 & .06 & .17 & .41 & 4.68 & .00 \\
\hline Bank Knowledge: Respect & $.72 * *$ & -.06 & .61 & .05 & -.17 & .04 & -1.16 & .25 \\
\hline Bank Knowledge: Ethics & $.59 * *$ & -.14 & .71 & .06 & -.26 & -.01 & -2.17 & .03 \\
\hline Bank Knowledge: Innovation & $.64 * *$ & .53 & .84 & .07 & .38 & .68 & 7.05 & .00 \\
\hline Communication: Respect & $.70 * *$ & -.35 & .69 & .06 & -.47 & -.23 & -5.74 & .00 \\
\hline Communication: Ethics & $.68 * *$ & -.44 & .69 & .06 & -.55 & -.31 & -6.90 & .00 \\
\hline Communication: Innovation & $.78 * *$ & .24 & .69 & .06 & .12 & .36 & 3.95 & .00 \\
\hline Respect: Ethics & $.76 * *$ & -.08 & .55 & .05 & -.17 & .02 & -1.53 & .13 \\
\hline Respect: Innovation & $.69 * *$ & .60 & .79 & .07 & .46 & .74 & 8.4 & .00 \\
\hline Ethical: Innovation & $.75 * *$ & .67 & .72 & .06 & .54 & .80 & 10.42 & .00 \\
\hline
\end{tabular}

**Correlation is significant at the 0.01 level (two-tailed)

95\% CI diff 95\% confidence interval of the difference between means, $L B$ lower bound, UB upper bound ethical than knowledgeable, reasonable communicators, and innovative. Bank customers also agreed more strongly that tellers treated them with respect and were knowledgeable than that they were reasonable communicators or innovative with respect to bank services.

Independent samples $t$ tests were used to address RQ2 and RQ3. Each participant is included in only one of the groups. The data must meet the $t$ tests assumptions of univariate normality, linearity, and homogeneity of variance (Weaver and Goldberg 2011). Effect sizes were calculated using Cohen's $d$ to assess the magnitude and practical importance of results (Weaver and Goldberg 2011), regardless of statistical significance. Cohen's $d$ divides the average (mean) difference between means by the standard deviation and is interpreted as small $(d=.20)$, medium $(d=.50)$, or large $(d=.80)$.

For RQ2, ratings were compared across gender with independent samples $t$ tests. The independent variable was gender. The dependent variables were the five leadership attributes and satisfaction.

The means in Table 4 indicate that females rated bank tellers higher on all five leadership attributes than did men,
Table 4 Means in leadership attributes and satisfaction by gender

\begin{tabular}{lllll}
\hline \multirow{2}{*}{ Bank Knowledge } & Gender & Mean & SD & SEM \\
& Male & 5.01 & 0.86 & 0.09 \\
Communication & Female & 5.41 & 0.62 & 0.10 \\
& Male & 4.70 & 0.96 & 0.10 \\
Respect & Female & 5.18 & 0.78 & 0.13 \\
& Male & 5.11 & 0.89 & 0.10 \\
Ethics & Female & 5.38 & 0.65 & 0.10 \\
& Male & 5.20 & 0.82 & 0.09 \\
Innovation & Female & 5.43 & 0.61 & 0.10 \\
\multirow{3}{*}{ Satisfaction } & Male & 4.50 & 1.10 & 0.12 \\
& Female & 4.82 & 1.03 & 0.17 \\
& Male & 5.01 & 0.96 & 0.10 \\
& Female & 5.51 & 0.61 & 0.10 \\
\hline
\end{tabular}

$n=88$ male customers, $n=38$ female customers

SEM standard error of the mean

and reported higher levels of satisfaction than did men as well.

Table 5 shows the results of the $t$ tests comparing men and women on leadership and satisfaction. In Table 5, 
Table $5 t$ Test results comparing leadership attributes and satisfaction by gender $(d f=124)$

\begin{tabular}{|c|c|c|c|c|c|c|c|c|}
\hline & \multirow[t]{2}{*}{$t$} & \multirow[t]{2}{*}{$d f$} & \multirow[t]{2}{*}{$p$} & \multirow[t]{2}{*}{ Cohen's $d$} & \multirow[t]{2}{*}{ Mean diff } & \multirow[t]{2}{*}{ SE diff } & \multicolumn{2}{|c|}{$95 \% \mathrm{CI}$} \\
\hline & & & & & & & LB & UB \\
\hline Bank Knowledge & -2.91 & 95.64 & .005 & .53 & -.39 & .15 & -.67 & -.13 \\
\hline Communication & -2.95 & 85.59 & .004 & .55 & -.48 & .16 & -.81 & -.16 \\
\hline Respect & -1.67 & 124 & .10 & .35 & -.27 & .16 & -.59 & .05 \\
\hline Ethics & -1.58 & 124 & .12 & .30 & -.23 & .15 & -.53 & .06 \\
\hline Innovation & -1.49 & 124 & .13 & .29 & -.31 & .21 & -.73 & .10 \\
\hline Satisfaction & -3.51 & 106.37 & .001 & .64 & -.50 & .14 & -.78 & -.22 \\
\hline
\end{tabular}

Levene Levene's test for equality of variances. Decimal forms of degrees of freedom correspond to corrections made for heterogeneity of variance in SPSS software, 95\% CI 95\% confidence interval of the difference, $L B$ lower bound of CI, $U B$ upper bound of CI

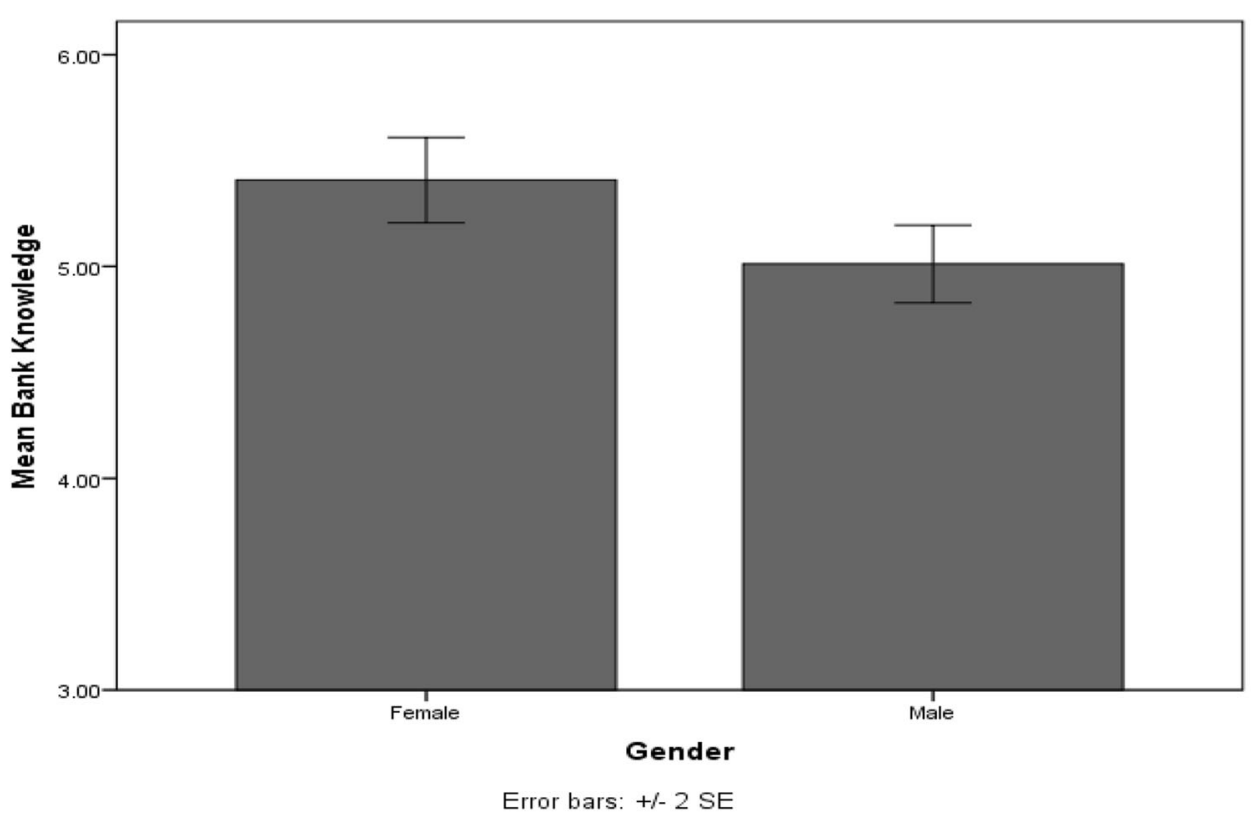

Fig. 3 Mean bank teller ratings of Bank Knowledge across gender $p$ values show that male and female customers rated bank tellers significantly differently on two leadership attributes, Bank Knowledge and Communication. Men and women also differed significantly on Satisfaction. Therefore, null hypotheses for these three measures were rejected. Thus, whereas all of the female ratings were higher than the men's ratings on Table 4, only these three were significantly higher. In contrast, the null hypotheses for Respect, Ethics, and Innovation were retained.

The means for Bank Knowledge are shown in Fig. 3. The effect of gender on ratings of Bank Knowledge was medium (see the Cohen's $d$ effect size statistic, Table 5).

The means for Communication are shown in Fig. 4. The effect of gender on ratings of Communication was medium (see the Cohen's $d$ effect size statistic, Table 5).

The means for Satisfaction are shown in Fig. 5. The effect of gender on ratings of Satisfaction was between medium and large (see the Cohen's $d$ effect size statistic, Table 5).

The answer to RQ2 was that ratings of two teller leadership attributes (Bank Knowledge and Communication) and customer satisfaction ratings differed by customer gender. Specifically, females rated tellers more highly than did males.

Pearson product-moment correlations were used to address RQ4. The sample size $(N=126)$ in this study was adequate for generating valid correlations. Gender was dummy coded $($ male $=0$, female $=1)$ for inclusion in correlations for RQ4.

RQ4 was addressed with correlations. Table 6 shows that Satisfaction correlated directly, strongly, and significantly with all five leadership attributes; therefore, the null hypotheses were rejected for these correlations. Therefore, relationships exist between bank teller leadership attributes and customer satisfaction and they are strong and direct. 
Fig. 4 Mean bank teller ratings of Communication across gender

Fig. 5 Mean bank teller ratings of Satisfaction across gender
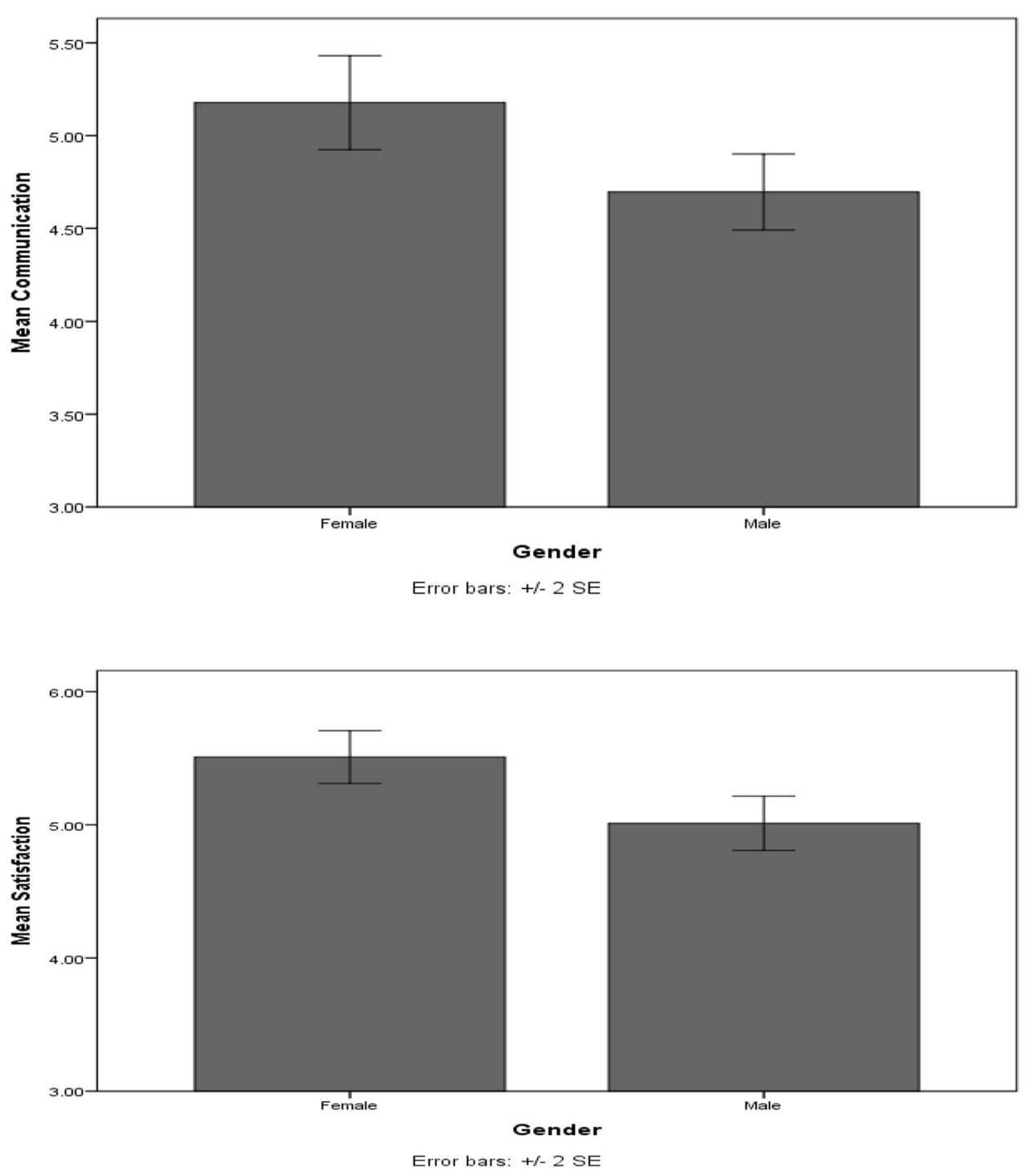

Among themselves, all five leadership attributes also showed direct, strong correlations. The strongest was between Innovation and Communication, followed by Ethics and Respect, and Innovation and Ethics.

Gender correlated significantly with Bank Knowledge, Communication, and Satisfaction.

The researcher used multiple regression to address RQ5. Results for RQ5 include results from a range of statistics that were examined for evidence of multicollinearity, as well as a number of other assumptions of regression (i.e., linearity, multivariate normality, normal distribution of residuals, multicollinearity, and autocorrelation). Gender was dummy coded (male $=0$, female $=1$ ) for inclusion in the regression for RQ5. Various combinations of predictor variables were entered into the equation using the stepwise entry method. This entry method systematically tests all possible combinations of variables until the predictor or combination of predictors with the greatest predictive power was found.

Unstandardized regression coefficients are used to show the weights of each significant factor (predictor) in the regression. In contrast, beta coefficients allow the relative contribution of significant predictors to be compared directly (Hair et al. 2010).

Partial correlations (symbolized as $p r$ ) among predictor variables were also reported with regression coefficients. These are measures of the association between two variables after the effects of one or more associated variables have been factored out. In the study, partial correlations refer to the relationship between a leadership attribute and satisfaction after the effects of other leadership attributes have been removed. Partial correlations are interpreted the same way as Pearson correlations are interpreted. Pearson zero-order correlations and partial correlations can be compared to determine the extent to which any zero-order 
Table 6 Pearson correlation matrix of leadership attributes, satisfaction, age, and years with the bank

\begin{tabular}{lcccccccc}
\hline & V1 & V2 & V3 & V4 & V5 & V6 & V7 & V8 \\
\hline V1 Bank Knowledge & 1 & & & & & & & \\
V2 Communication & $.69^{* *}$ & 1 & & & & & & \\
V3 Respect & $.72^{* *}$ & $.70^{* *}$ & 1 & & & & & \\
V4 Ethics & $.59 * *$ & $.68^{* *}$ & $.76^{* *}$ & 1 & & & & \\
V5 Innovation & $.64^{* *}$ & $.78^{* *}$ & $.69^{* *}$ & $.75^{* *}$ & 1 & & & \\
V6 Satisfaction & $.67^{* *}$ & $.66^{* *}$ & $.73^{* *}$ & $.73^{* *}$ & $.73^{* *}$ & 1 & & \\
V7 Age (years) & -.11 & $-.19^{*}$ & -.05 & -.17 & -.15 & -.15 & 1 & \\
V8 Years with bank & -.06 & .02 & -.02 & .05 & -.01 & -.03 & $.40^{* *}$ & 1 \\
V9 Gender & $.22^{*}$ & $.24^{* *}$ & .15 & .14 & .13 & $.26^{* *}$ & -.13 & -.14 \\
\hline
\end{tabular}

*Correlation is significant at the 0.05 level (two-tailed). **Correlation is significant at the 0.01 level (twotailed)

$d f=124 ; N=126$ correlation was mediated by the effects of other associated variables.

For RQ5, a multiple regression was run to determine the extent to which satisfaction could be predicted from leadership attributes and customer gender. Data must meet a number of assumptions in order for multiple regression results to be credible. This section shows that the bank teller data met the assumptions of regression. An assumption of multiple regression is that each pair of variables has a linear relationship. All scatter plots of the relationship between Satisfaction and the predictor variables were examined visually (not shown). All showed a linear relationship, indicating that the data met the regression assumption of linearity. Also, an assumption of multiple regression is that there are no multivariate outliers in the database. Multivariate outliers are identified with a statistic called the Mahalanobis distance. This statistic is based on the critical value of the Chi-square statistic $\left(\chi^{2}\right)$ for the number of predictor variables to be entered into the regression at the significance level of $p=.001$. For the bank teller data, there were six predictor variables (i.e., the five leadership attributes and customer gender); any participants with Mahalanobis distances equal to or greater than the value of $\chi^{2}=22.46$ were possible outliers. Two multivariate outliers were identified. Case 96 was possibly an outlier due to an extremely low Innovation rating (Mahalanobis distance $=23.93$, Bank Knowledge $=3.50$; Communication $=4.50 ; \quad$ Respect $=4.25, \quad$ Ethics $=5.25$, and Innovation $=1.75$ ). Case 100 was possibly an outlier due to an extremely low Respect rating (Mahalanobis distance $=38.53$, Bank Knowledge $=4.00$; Communication $=3.25$; Respect $=2.00$, Ethics $=4.75$, and Innovation $=5.00$ ). Regressions were run with and without the outliers, but the difference in the two results was negligible so the outliers are included in the final analysis.

Furthermore, an assumption of multiple regression is that the difference between each bank customer's observed value and the value that was predicted for that customer from the regression formula (i.e., the residual) were normally distributed and thus met the assumption of residual homoscedasticity. This assumption was checked with a visual inspection of a scatter plot of the standardized predicted values and residuals, shown in Fig. 6. The bank teller data residuals met the assumption of homoscedasticity.

In the study, predictor variables potentially included the five leadership attributes and customer gender. An assumption of multiple regression is that none of the predictor variables strongly correlate with any other predictor variable. When two predictor variables correlate, the condition is called collinearity. When more than two predictor variables correlate, this condition is known as multicollinearity. Multicollinearity is avoided in multiple regression because predictor variables that are highly correlated with each other cannot both make unique contributions to prediction.

Four measures were inspected to evaluate multicollinearity among the predictor variables. One, multicollinearity is the condition of two or more predictor variables that are strongly correlated, which Hair et al. (2010) defined as $r=.70$ or greater. Table 6 shows that the only correlations among the predictor variables (leadership V1-V5, and gender V9 on Table 6) that did not meet or come close to Hair et al.'s criterion were between Bank Knowledge and Ethics, and between Bank Knowledge and Innovation. This suggested the wisdom of using the entry method to do the regression so that calculations could identify the variables that did the best job of prediction. Two, condition statistics derived from factor analysis were inspected (see Table 7). Condition statistics that range from 10 to 30 indicate mediocre multicollinearity, whereas values $>30$ indicate strong multicollinearity. The condition statistics shown in Table 7 range from 2.63 to 26.82, indicating that multicollinearity was not an issue. Three, 
Fig. 6 Scatter plot of the standardized predicted values and residuals for satisfaction with bank tellers

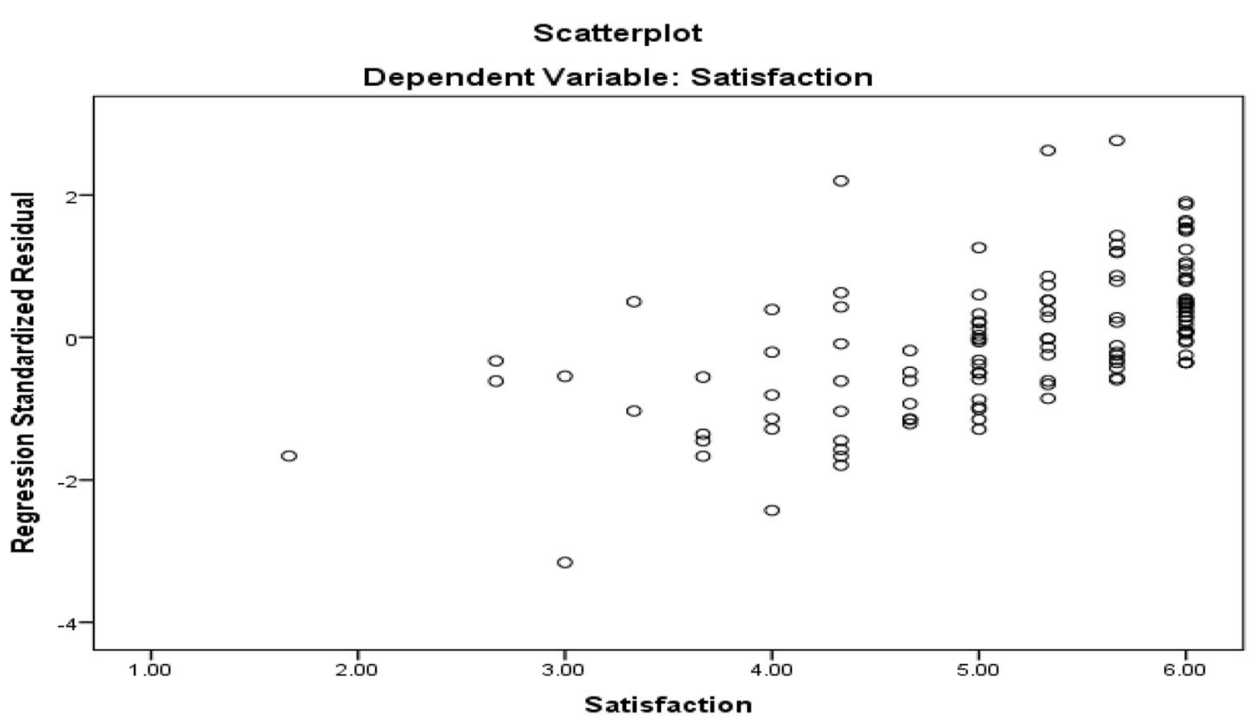

\begin{tabular}{llllllll}
\hline Dimension & Eigenvalue & Condition index & \multicolumn{6}{l}{ Variance proportions } \\
\cline { 3 - 7 } & & & Constant & Ethics & Bank knowledge & Innovation & Gender \\
\hline 1 & 4.33 & 1.00 & .00 & .00 & .00 & .00 & .02 \\
2 & .62 & 2.63 & .00 & .00 & .00 & .00 & .95 \\
3 & .02 & 12.68 & .24 & .00 & .01 & .43 & .00 \\
4 & .01 & 20.74 & .16 & .12 & .98 & .05 & .02 \\
5 & .006 & 26.82 & .59 & .88 & .02 & .52 & .00 \\
\hline
\end{tabular}

Table 7 Collinearity diagnostics for predictor variables of satisfaction with bank tellers than mean Satisfaction was of predicting satisfaction with bank tellers. The specific hypotheses were as follows:

$\begin{array}{ll}\mathrm{H}_{0} & R^{2}=0 \\ \mathrm{H}_{1} & R^{2}>0\end{array}$

The second set of hypothesis test the prediction that the slope of the regression line is something other than zero (i.e., is not horizontal). The specific hypotheses were as follows:
$\mathrm{H}_{0} \quad$ Beta $=0$
$\mathrm{H}_{1} \quad$ Beta $\neq 0$

Results showed that the regression model explained a statistically significant $66 \%$ of the variance in Satisfaction, $R^{2}=.66, F(4,121)=59.83, p<.001$. The $R^{2}=0$ null hypothesis was rejected. The unstandardized coefficients in Table 8 show that Ethics, Bank Knowledge, Innovation, and Gender all made unique and statistically significant contributions to predicting Satisfaction with bank tellers. The Beta $=0$ null hypothesis was rejected for these predictors.

A comparison of the standardized coefficients in Table 8 shows that Ethics was the strongest predictor of Satisfaction. Further, the comparison shows that Innovation and 
Table 8 Regression coefficients for predicting satisfaction with bank tellers from their leadership attributes

\begin{tabular}{|c|c|c|c|c|c|c|c|c|c|}
\hline \multirow[t]{2}{*}{ Model } & \multicolumn{2}{|c|}{ Unstandardized coefficients } & \multirow{2}{*}{$\begin{array}{l}\text { Standardized coefficients } \\
\text { Beta }\end{array}$} & \multirow[t]{2}{*}{$t$} & \multirow[t]{2}{*}{$p$} & \multicolumn{2}{|c|}{ Correlations } & \multicolumn{2}{|c|}{ Collinearity statistics } \\
\hline & $B$ & SE & & & & $r$ & $\mathrm{pr}$ & Tolerance & VIF \\
\hline Constant & .42 & .37 & & 1.15 & .252 & & & & \\
\hline Ethics & .41 & .09 & .35 & 4.37 & .000 & .73 & .37 & .41 & 2.38 \\
\hline Bank Knowledge & .27 & .07 & .25 & 3.53 & .001 & .66 & .30 & .54 & 1.82 \\
\hline Innovation & .23 & .07 & .28 & 3.34 & .001 & .72 & .29 & .38 & 2.60 \\
\hline Gender & .21 & .10 & .11 & 2.07 & .040 & .25 & .18 & .94 & 1.054 \\
\hline
\end{tabular}

$\mathrm{r}=$ zero order, $\mathrm{pr}=$ partial

Bank Knowledge made roughly comparable predictions. Finally, Gender differentiated satisfaction and improves predictions about satisfaction with bank tellers when taken into account, though its contribution to prediction was modest.

Because gender was a significant predictor, there are two regression formulas (one for females and one for males). For female customers, the regression formula for predicting satisfaction was as follows:

Predicted Female Satisfaction with Bank Tellers

$$
\begin{aligned}
= & 0.42+.41(\text { Ethics rating }) \\
& +.27(\text { Bank Knowledge rating }) \\
& +.23(\text { Innovation rating })+.21
\end{aligned}
$$

For male customers, the regression line for predicting satisfaction was as follows:

Predicted Male Satisfaction $=0.42+.41($ Ethics rating $)$

$$
\begin{aligned}
& +.27 \text { (Bank Knowledge rating) } \\
& +.23 \text { (Innovation rating) }
\end{aligned}
$$

\section{Conclusions}

For RQ1, the null hypothesis stated that there is no significant difference in the ratings of the five leadership attributes. When the means of leadership attributes were compared using descriptive statistics, it indicated that Ethics was rated the highest leadership attribute by customers, followed by Respect, Bank Knowledge, and Communication, while Innovation was rated the lowest. Furthermore, a repeated measure ANOVA showed that there is significant difference within and between the five leadership attributes with a very strong effect. Therefore, bank customers felt tellers were more ethical and respectful than knowledgeable. Customers also rated the tellers as more reasonable communicators than innovative.

When comparing means of the five leadership attributes and satisfaction; the findings indicated that females rated
Table 9 Absolute value ranges for RQ5

Strength $r$ value

Very weak $0-.19$

Weak .20-.39

Moderate .40-.59

Strong .60-.79

Very strong $.80-1.0$

bank tellers differently than did males with respect to leadership attributes and customer satisfaction. However, based on the $p$ values generated from the $t$ test, females rated bank tellers significantly different on Bank Knowledge, Communication, and satisfaction.

Therefore, for those three variables the null hypotheses were rejected. On the contrary, for the Respect, Ethics, and Innovation attributes, the null hypotheses were retained based on the $p$ values being greater than .05 (see Table 5). Additionally, the effect of gender on ratings of Bank Knowledge was medium, (see Cohen's $d$ effect size values in Table 5). Cohen (1988) defined effect sizes as small, $d=.2$, medium, $d=.5$, and large, $d=.8$.

The effect of gender on ratings of Communication was medium, and the effect of gender on the ratings of satisfaction was between medium and large. Based on the correlation matrix, for RQ4 the correlations between each leadership attribute and customer satisfaction was positive, strong, and significant; therefore, the null hypothesis was rejected based on the absolute value ranges of $r$ (see Table 9).

The correlations within the leadership attributes mean that respondents who rated bank tellers with high communication skills also rated them as highly innovative. Similarly, customers who rated bank tellers as highly ethical also rated them with high people skills (Respect). Age and years as a customer with the bank were also included to see if they correlated with leadership or satisfaction. Age did not correlate with any attribute of leadership except Communication, and even then, the association was small 
to moderate. The variable, years as a customer with the bank, did not correlate with leadership attributes or satisfaction, but showed a direct and moderate association with age. Gender correlated significantly with Bank Knowledge, Communication, and satisfaction. The findings for RQ5 were achieved through multiple regression analysis. The multiple regression results revealed that $66 \%$ of customer satisfaction can be predicted or explained by the ethical behavior of tellers, their bank knowledge, their innovative attributes, and customer gender whereas $R 2=.66$. The null hypothesis was rejected, whereas the $p$ value was less than .001. Ethics, Bank Knowledge, Innovation, and customer gender all made unique and statistically significant contributions to customer satisfaction.

\section{Implications and recommendations}

Responses to the open-ended survey question to gather feedback on how bank management could improve their overall services included $30 \%$ of respondents $(n=38)$ suggested that the bank should improve teller speed and nearly $37 \%(n=14)$ of the $30 \%$ suggested increasing the number of tellers in each branch. Nearly $33 \%(n=41)$ of participants stated that tellers lack comprehensive banking product knowledge outside the teller domain, and more than half of those suggested that comprehensive training for tellers was needed. Nearly $6 \%(n=7)$ of participants suggested maintaining the same tellers and not continuously changing them. Thus, it is recommended to hire at least one teller and keep her/him in permanently per bank branch to keep a familiar person to get acquainted with the regular customers and their needs. Moreover, nearly $21 \%$ $(n=26)$ of participants recommended improvement in teller communication and people skills. Some respondents told this researcher that some tellers, but not all, lack people skills and the ability to communicate well in general as well as to communicate benefits of banking products and services in particular. Participants also suggested that training is needed to improve communication both in-person and over the phone with customers.

\section{Researcher recommendations}

During the recruiting as well as training processes, the Ethics attribute of tellers should be regarded as most important. Thus, training would be of great benefit to tellers to emphasize the importance of ethics in banking. Also, recruiting skilled communicators as well as training tellers to improve such leadership attributes. Furthermore, the Respect attribute of tellers' ratings by customers was not significantly different when compared with the Ethics attribute. A likely implication of this result is that customers may have viewed respect as a measure of ethics. According to Philip Pettit, a Princeton philosopher, attachment, virtue, and respect are the three classes of ethics as each is unique from the other two classes (Thompson 2016). Results of this study revealed that there is no significant difference in the ratings between the Respect attribute of tellers by customers and Bank Knowledge attribute ratings. A possible implication may be that when tellers build good rapport with customers, although some may not have all the knowledge desired about all bank products, the customers either choose to overlook any lack of knowledge or assume the teller is knowledgeable when they are respectful with desired people skills. Consequently, the Respect and Bank Knowledge attributes, according to findings, were strongly and directly correlated (.72). Interestingly, the correlation matrix revealed that there was a higher correlation between the Respect attribute and customer satisfaction (.73) than between Bank Knowledge and customer satisfaction (.67) which implied that customers would be more satisfied with the people skills and the respectful behaviors of tellers than they were satisfied with the tellers' Bank Knowledge.

Based on anecdotal conversations with respondents, the majority of respondents disclosed that tellers rarely try to market other bank services or products that may be of benefit to the customer. Many customers expressed that they did not know that tellers were supposed to market bank products according to their needs. Similarly, the branch managers also disclosed to this researcher that tellers scarcely try to market beneficial bank products to customers which part of their job duties. The implications of such statements may be pertinent to the Communication attribute and the gender differences that play a major role in communicating effectively with customers. The Communication attribute correlated directly and strongly with customer satisfaction, and Communication and Innovation also correlated directly and strongly with Innovation. The aforementioned statements imply the importance of the Communication attribute of tellers, and this attribute should not be ignored by bank management.

Gender differences in customer ratings also must be considered by management to improve communication and to enhance customer satisfaction. Jordan is a predominantly Muslim population; there are restrictive codes of female conduct as it links family honor to female virtue, and it is a culture that prefers covering female heads and implementing sex segregation as a preferred gender system (Offenhauer 2005). Due to this conservative culture where this study took place in Amman, Jordan, a possible explanation for females' higher ratings is that female tellers are more at ease when communicating information with female rather than male customers. However, not all 
Jordanian females come from very conservative families, which may alter the way such females communicate with male customers. Consequently, it is recommended to keep in mind these gender differences when recruiting tellers, knowing that the choice may impact communication effectiveness with customers. Additionally, such gender differences may also contributed to the fact that females have different bank behavior than males; it is recommended that bank management address such point by further exploring patterns of banking behavior based on gender in Amman, Jordan, and direct tellers based on the findings, as they market bank products.

Open Access This article is distributed under the terms of the Creative Commons Attribution 4.0 International License (http://crea tivecommons.org/licenses/by/4.0/), which permits unrestricted use, distribution, and reproduction in any medium, provided you give appropriate credit to the original author(s) and the source, provide a link to the Creative Commons license, and indicate if changes were made.

\section{References}

Al-jazzazi, A. 2017. Demographic differences in Jordanian bank service quality perceptions. International Journal of Bank Marketing. https://doi.org/10.1108/IJBM-07-2016-0091.

Ambroz, M., and M. Praprotnik. 2008. September). Organisational effectiveness and customer satisfaction. Organizacija 41 (5): 161-173. https://doi.org/10.2478/v10051-008-0018-2.

Badshah, S. 2012. Historical study of leadership theories. Journal of Strategic Human Resource Management 1 (1): 49-59.

Baldoni, J. 2008. 50 Ways great leaders inspire results. [Digital Bookshelf]. Retrieved from http://site.ebrary.com.libproxy. edmc.edu/lib/argosy/detail.action?docID=10271818.

Banther, B. 2014. Five qualities of a lasting leader. Health Care Registration: The Newsletter for Health Care Registration Professionals 23 (7): 6-7.

Cheema, S., A. Akram, and F. Javed. 2015. Employee engagement and visionary leadership: Impact on customer and employee satisfaction. Journal of Business Studies Quarterly 7 (2): 139-148.

Coelho, P.S., and J. Henseler. 2012. Creating customer loyalty through service customization. European Journal of Marketing 46 (3/4): 331-356. https://doi.org/10.1108/03090561211202503.

Cohen, J.W. 1988. Statistical power analysis for the behavioral sciences, 2nd ed. Hillsdale: Lawrence Erlbaum.

Covey, S.R. 1989. The seven habits of highly effective people. New York: Free Press.

Doss, S.K. 2014. "Spreading the good word": Toward an understanding of brand evangelism. Journal of Management and Marketing Research 14: 1-16.

Georgescu, P., and Dorsey, D. 2005. The source of success: Five enduring principles at the heart of real leadership, 1st edn [EBSCOhost].

Graefe, A.R., and R.C. Burns. 2013. Testing a mediation model of customer service and satisfaction in outdoor recreation. Journal of Outdoor Recreation and Tourism 3-4: 36-46. https://doi.org/ 10.1016/j.jort.2013.09.006.

Hair Jr., J.F., W.C. Black, B.J. Babin, R.E. Anderson, and R.L. Tatham. 2010. Multivariate data analysis, 785. Upper Saddle River: Prentice Hall.
Hsu, D.K., R.S. Shinnar, and B.C. Powell. 2014. Expecttancy theory and entrepreneurial motivation: A longitudinal examination of the role of entrepreneurship education. Journal of Business and Entrepreneurship 26 (1): 121-140.

Hui, E.C., Z. Pei-hua, and X. Zheng. 2013. Facilities management service and customer satisfaction in shopping mall sector. Facilities 31 (5/6): 194-207. https://doi.org/10.1108/ 02632771311307070.

Indo Asian News Service (IANS). 2015, October. Customer feedback can spur employees' creativity. IANS English; New Delhi.

Jackson, D. 1993, February. Your next choice: Compare customer service with customer satisfaction. Life \& Health Insurance Sales 136 (2).

Karlsson, J., and P. Skålén. 2015. Exploring front-line employee contributions to service innovation. European Journal of Marketing 49 (9/10): 1346-1365.

Landis, E.A., D. Hill, and M.R. Harvey. 2014. A synthesis of leadership theories and styles. Journal of Management Policy and Practice 15 (2): 97-100.

Lee, S. 2007. Vroom's expectancy theory and the public library customer motivation model. Library Review 56 (9): 788-796. https://doi.org/10.1108/00242530710831239.

Leelawong, R. 2011. Managing employee ideas and creativity in Thailand: Challenges and key factors for success. Doctoral dissertation.

Li, N., and W.H. Murphy. 2013. Prior consumer satisfaction and alliance encounter satisfaction attributions. The Journal of Consumer Marketing 30 (4): 371-381. https://doi.org/10.1108/ JCM-05-2013-0569.

Liang, C., and W. Wen-Hung. 2004. Attributes, benefits, customer satisfaction and behavioral loyalty-An integrative research of financial services industry in Taiwan. Journal of Services Research 4 (1): 57-68,72-91.

Medina, R. 2010. Quantitative descriptive correlational research study on customer service leadership skills and customer satisfaction. Doctoral dissertation.

Mokhlis, S. 2012. The influence of service quality on satisfaction: A gender comparison. Canadian Center of Science and Education 1 (1): 103-112. https://doi.org/10.5539/par.v1n1p103.

Nelson, D. 2013. Management works in the system; leadership works on the system "the interpersonal skills on corporate threshold. Language in India 13 (4): 22-31.

Offenhauer, P. 2005, November. Women in Islamic societies: A selected review of social scientific literature. The Library of Congress 1-119. Retrieved from https://www.loc.gov/rr/frd/pdffiles/Women_Islamic_Societies.pdf.

Okoe, A.F., J.S. Adjei, and A. Osarenkhoe. 2013. Service quality in the banking sector in Ghana. International Journal of Marketing Studies 5 (2): 81-92.

O'Sullivan, D., and J. McCallig. 2012. Customer satisfaction, earnings and firm value. European Journal of Marketing 46 (6): 827-843. https://doi.org/10.1108/03090561211214627.

Raab, G., R.A. Ajami, and V.B. Gargeya. 2012. Customer relationship management [Digital Bookshelf].

SurveyMonkey. 2016. Survey sample size calculator. Retrieved from http://fluidsurveys.com/survey-sample-size-calculator/.

Thompson, M.J. 2016. Review: Philip Pettit. The robust demands of the good: Ethics with attachment, virtue and respect. Oxford University Press 47 (1): 117-121. https://doi.org/10.1111/phil.12107.

Warner, R. M. (2013). Applied statistics: From bivariate through multivariate techniques (2nd ed.). Thousand Oaks, CA: SAGE Publications, Inc.

Weaver, A., and S. Goldberg. 2011. Clinical biostatistics and epidemiology made ridiculously simple. Miami: MedMaster Pub.

Woolfe, L. 2002. Bible on leadership: From Moses to Matthewmanagement lessons for contemporary leaders [Digital Bookshelf]. 